\title{
Second Generation Nuclear-Weapon-Free Zone: Mixing Noble Ideas and Hard Reality
}

\author{
By Hiromichi Umebayashi (Japan)
}

\section{Second Generation NWFZs}

$\mathrm{A}^{\mathrm{n}}$

Nuclear-Weapon-Free Zone (NWFZ) is a manifestation of international or regional efforts to limit nuclear weapons - the most destructive weaponry humankind has ever created. However, a NWFZ is meant to achieve more than this. The objectives of a NWFZ include not only limiting nuclear weapons, but also making a significant contribution to maintenance of intemational peace and security in areas with varied historical backgrounds, some with longstanding disputes. In order to attain such objectives to ensure regional security in a broader sense, NWFZs have been pursued, achieved and maintained. As is well known, currently there are five NWFZs, each established and governed by an intemational treaty and named after the place associated with their negotiation. They are Latin America and the Caribbean NWFZ stipulated by Tlatelolco Treaty, South Pacific NFZ stipulated by Rarotonga Treaty, Southeast Asia NWFZ stipulated by Bangkok Treaty, African NWFZ stipulated by Pelindaba Treaty and Central Asia NWFZ stipulated by Semipalatinsk Treaty.

Besides these established zones, there have been ideas and proposals for new NWFZs that are still relevant today, such as Middle East Zone Free of Nuclear Weapons as well as Other Weapons of Mass Destruction (WMD), South Asia NWFZ, Central Europe NWFZ and Northeast Asia NWFZ.

The Middle East NWFZ was first proposed by Iran supported by Egypt in 1974. Since that time the UN General Assembly has adopted the resolution to support the idea every year. In 1990, President Mubarak of Egypt proposed an extended idea of the Middle East Zone Free of 
WIM. The Middle East Resolution adopted at the 1995 NPT Review and Extension Conference calls upon all states parties to NPT to make efforts to ensure the establishment of such zone. Among the well known difficult issues in relation to the Middle East NWFZ are Israeli nuclear capabilities and unsafeguarded nuclear activities outside the NPT and Iranian uranium enrichment and spent fuel reprocessing programs, both under the sustained military tension between Israel and Arabic nations.

Since the Indian nuclear test in 1974, a South Asia NWFZ has been a subject of UN General Assembly. A proposal of such zone is to encompass seven states that are members of the South Asian Association for Regional Cooperation (SAARC), i.e. Bangladesh, Bhutan, India, the Maldives, Nepal, Pakistan, and Sri Lanka. However, after the successive nuclear tests by India and Pakistan in 1998, the idea was forced to come to a deadlock. However, the civil society in the region continues to pursue the realization of the NWFZ as a goal for denuclearization of India and Pakistan. Both countries have not acceded to the NPT and have unsafeguarded nuclear facilities. India considers nuclear weapons essential for national security in the world where some nations are allowed to possess such weapons for the indefinite period of time. Pakistan considers nuclear weapons necessary to deter the India's intent of aggression.

The Central Europe NWFZ was first proposed by Soviet Union in 1956 and so called Rapacki-plan was presented by Poland in 1957 to make Poland, Czechoslovakia, East and West Germany nuclear-free. After the end of the Cold War, a new idea was introduced by Belarus in 1995 and later backed by Ukraine to make Central and Eastern Europe NWFZ (CEE-NWFZ) from the Black Sea to the Baltic Sea. This initiative might draw more attention in light of the recent tension between Russia and eastward expanded NATO.

Regarding the Northeast Asia nuclear weapons, ideas and the history have already been discussed in this conference.

When comparing the case of these potential NWFZs with that of the existing five zones, we see obvious "obstacles" to achieve such new zones. Namely, in this case, nuclear weapons have already built in to the security policy in some of the key countries involved. In some cases, so-called de facto nuclear-weapon holders (India, Pakistan and Israel) or claimant nuclear-weapon holders (DPRK) are involved. In some cases, 
some non-nuclear countries adopt their security policy dependent on the extended nuclear deterrence of the nuclear powers, especially of the United States, including hosting permanent military bases on their own soil. Also in some cases, some non-nuclear countries are vulnerable to strong political influence of the nuclear super powers. It is true that the political pressure from the super powers is nothing new in developing a NWFZ, as we see a recent example in the case of Central Asia NWFZ, but in some cases in question it will be outstanding. Because of such common features, we may call these prospective NWFZs "Second Generation NWFZs."

\section{Nuclear-Weapon Dependent Non-Nuclear Countries}

In the following, I would like to focus on the issue of the nonnuclear countries that adopt declared security policy to depend upon the extended deterrence of the nuclear weapon states, namely "nuclearweapon dependent non-muclear countries," as it is related to the potential constituents of a NEA-NWFZ, including my own country Japan. There are 26 such countries, namely 23 non-nuclear NATO countries, including Germany, Italy and new members after NATO eastward expansion, and three U.S. allies in the Asia-Pacific; Australia, the ROK and Japan.

The most recent NATO's strategic document "The Alliance's Strategic Concept," adopted at the 1999 NATO sumit, describes the role of nuclear weapons in the Alliance as follows: "The supreme guarantee of the security of the Allies is provided by the strategic nuclear forces of the Alliance, particularly those of the United States; the independent nuclear forces of the United Kingdom and France, which have a deterrent role of their own, contribute to the overall deterrence and security of the Allies" (Para. 62). Also it describes the requirement of the participation of the member countries in such nuclear roles as follows: "A credible Alliance nuclear posture and the demonstration of Alliance solidarity and common commitment to war prevention continue to require widespread participation by European Allies involved in collective defense plaming in nuclear roles, in peacetime basing of nuclear forces on their territory and in command, control and consultation arrangements" (Para. 63). This basic document remains valid today.

In case of Australia, the most recent Defence White Paper "Defence 2000 - Our Future Defence Force" states, after emphasizing that Australia's relationship with the United States "should not be a 
relationship of dependency" and that "self-reliance will remain an inherent part of its alliance policy," "There is one important exception to this principle of self-reliance. Australia relies on the extended deterrence provided by US nuclear forces to deter the remote possibility of any nuclear attack on Australia." The White Paper "Defence 2000" has been updated twice since then, in 2003 and in 2005. There is no reference to the extended deterrence in either updates. However, it will not mean there was a policy change, because the updates in these cases were not the replacement of the previous document but only the addition to adapt to the change of the security environment. I will discuss more on the Australian case in relation to its participation in the South Pacific NWF Z .

The ROK's reliance on the US extended nuclear deterrence has repeatedly been confirmed in the US-ROK bilateral Security Consultative Meeting (SCM) between the defense ministers of the two countries. The most recent SCM Joint Communique on 20th October 2006, ten days after the DPRK nuclear test, reads "Secretary Rumsfeld offered assurances of firm U.S. commitment and immediate support to the ROK, including continuation of the extended deterrence offered by the U.S. nuclear umbrella, consistent with the Mutual Defense Treaty."

The most recent version of the Japan's "National Defense Program Outline, FY 2005-" issued in December 2004, describes its nuclear policy as follows, after ensuring its adherence to the three non-nuclear principles, "To protect its territory and people against the threat of nuclear weapons, Japan will continue to rely on the U.S. nuclear deterrent. At the same time, Japan will play an active role in creating a world free of nuclear weapons by taking realistic step-by-step measures for nuclear disarmament and non-proliferation." This U.S. nuclear umbrella was reconfirmed in the most recent Joint Statement of the Security Consultative Committee (SCC) attended by foreign and defense ministers of both countries in May 2007. It reads "U.S. extended deterrence underpins the defense of Japan and regional security. The U.S. reaffirmed that the full range of U.S. military capabilities - both nuclear and non-nuclear strike forces and defensive capabilities - form the core of extended deterrence and support U.S. commitments to the defense of Japan."

All these governmental official documentation demonstrates that the nuclear dependent non-nuclear countries believe in the nuclear 
deterrence no less than the muclear armed countries. In this circumstance, they would logically go nuclear if the nuclear umbrella is removed as is often mentioned with reference to Japan. If the nuclear threats are morally unacceptable, then the protection by nuclear umbrella is morally unacceptable as well. Moreover, in order to maintain the umbrella, they will not be able to press nuclear powers to disarm. Therefore, to establish a NWFZ involving nuclear dependent non-nuclear weapon states will provide such states with the solid and moral ground to play an essential role in nuclear disarmament.

\section{Compliance with the NPT Obligations for Non-Nuclear State Parties}

This brings us to an important argument on how to encourage nuclear dependent non-nuclear countries to establish a NWFZ.

The norms that govern the NPT regime at present should come from the "unequivocal undertaking by the nuclear weapon states to accomplish the total elimination of nuclear weapons," as is agreed in the final document adopted by consensus at the 2000 NPT Review Conference. Both the concluding recommendation in June 2006 by the WMD Commission chaired by Hans Blix and the concluding remark by Former UN Secretary General Kofi Annan at Princeton University in November 2006 are manifestations of such norms. The WMD Commission recommends that "all states possessing nuclear weapons should commence planning for security without nuclear weapons. They should start preparing for the outlawing of nuclear weapons through joint practical and incremental measures that include definitions, benchmarks and transparency requirements for nuclear disarmament." Kofi Annan "calls on all the states with nuclear weapons to develop concrete plans - with specific time tables - for implementing their disarmament commitments," and urges "them to make a joint declaration of intent to achieve the progressive elimination of all nuclear weapons, under strict and effective intemational control."

In fact, the same messages are to be directed to the nuclear dependent non-nuclear countries. The political obligation under the NPT is imposed not only to nuclear weapon states but also to their non-nuclear allies. When nuclear weapon states undertake to accomplish the total elimination of their nuclear arsenal, nuclear dependent non-muclear states have to commence planning for security without dependence on nuclear weapons, and to develop concrete plans - with specific time tables - for implementing their goal of security independent of nuclear weapons. 
The excellent approach for this purpose will to cormence negotiation to establish a relevant NWFZ.

Here we need an additional deliberation. To be a party to a NWFZ treaty does not mean not to rely upon nuclear weapons in its security policy, though it is an important step toward the end of non-reliance. For instance, Japanese conservatives will request the continuation of the current U.S. posture to deter non-nuclear attack against Japan (massive conventional, chemical and biological) by means of the U.S. nuclear weapons. This kind of deterrence posture will not be forced to change by the establishment of any of the NWFZs unless new kind of provisions is introduced to the treaty.

However, such posture will constitute a violation of the political commitment of the "diminishing role for nuclear weapons in security policies," which was also agreed to by consensus at the 2000 NPT Review Conference. Under an effective NWFZ treaty with a negative security assurance provision, any nuclear attack by any of five muclear weapon states against states within the zone is illegal under intemational law. Therefore, only non-nuclear attacks are assumed to be deterred in extended deterrence posture (or nuclear umbrella). This will mark a new stage of nuclear weapon usage at which nuclear weapons serve as a tool purely against non-nuclear weapons. Not only such disproportional use or threat of use of nuclear weapons is illegal under international law, but also it will make total elimination of nuclear weapons remote until general and complete disarmament is achieved.

In this context, I want to call your attention to the case of Australia that is under South Pacific NWFZ and the U.S. nuclear umbrella at the same time. Negative security assurance provision of the South Pacific NWFZ has been ratified by all the nuclear weapon states except for the U.S. So the purpose and reason of the extended nuclear deterrence provided by the U.S. is very difficult to understand. It seems to be designed to work against non-nuclear attack. It is recommended, therefore, that a second generation NWFZ treaty includes a provision that prevents such situation from happening. Provisions to stipulate for non-nuclear state party's undertaking of non-reliance upon nuclear weapons in its security policy or their rejection of first-use by nuclear weapon states in conflicts involving non-nuclear state parties within the zone might work. Otherwise, a protocol signed by nuclear weapon states concerned could provide that they do not use nuclear weapons in any armed conflicts involving non-nuclear state parties to a NWFZ treaty. 